\title{
RECORDANDO A FRANÇOIS FÉDIER
}

\author{
François Fédier nació en 1935 en París y murió \\ en la misma ciudad el 28 de abril de 2021. \\ Jorge Acevedo Guerra \\ Universidad de Chile \\ joaceved@u.uchile.cl
}

\begin{abstract}
RA Lo conocí a mediados de 1973, en la Escuela de Arquitectura de la Universidad Católica de Valparaíso. Tuve la fortuna de asistir a dos seminarios que dio allí. Uno sobre las tesis a Feuerbach de Marx y otro sobre Arthur Rimbaud. En ese momento me llamaron profundamente la atención algunas ideas en torno a las que Fédier hacía pensar. Una fue "hay que ser absolutamente modernos", de Rimbaud. Otra, "hablar por hablar, tal es la fórmula de la liberación", de Novalis. Un tanto extrañado, me preguntaba si este joven profesor, acompañado de sus estudiantes de khâgne-varones y mujeres-, no se estaría saltando la crítica de Heidegger a la modernidad y su puesta en cuestión del se dice, del habla cotidiana. El hecho de que usara pantalones pata de elefante aumentaba mi extrañeza aldeana frente al visitante. Por suerte, la admiración y respeto que suscitaba entre grandes maestros de la filosofía en Chile hicieron que tal suspicacia se disipara rápidamente.

Fue discípulo de Jean Beaufret y Martin Heidegger. Estuvo encargado de la publicación de la Edición integral (Gesamtausgabe) de este último en la Editorial Gallimard de París. La tarea le fue confiada por el mismo Heidegger.

Codirigió Le Dictionnaire Martin Heidegger. Vocabulaire polyphonique de sa pensée. Entre sus numerosas obras se cuentan Interprétations, Voix de l'ami, Totalitarismo e nichilismo.

Trabajó estrechamente con Heidegger en la etapa final de la vida del filósofo. Así, por ejemplo, en los seminarios de Thor (1966, 1968 y 1969), efectuados en Francia, y en el de Zähringen (1973), realizado en Alemania. Los protocolos de estos importantes seminarios han sido recogidos en el volumen 15, Seminare, de la Edición integral ${ }^{1}$. En francés, aparecen en la obra de Heidegger titulada Questions $\mathrm{IV}^{2}$.
\end{abstract}


Hay dos libros suyos en castellano: Voz del amigo y otros ensayos en torno a Heidegger ${ }^{3}$ y Cinco intentos filosóficos ${ }^{4}$. A propósito de la publicación de Voz del amigo, Juan Rodríguez Medina lo entrevista a través del correo electrónico. El texto correspondiente aparece en "Artes y Letras" de El Mercurio de Santiago (27 de agosto de 2017, p. E-6).

Rodríguez dice allí que en 1958, Heidegger visitó la Universidad de Aix-enProvence, en el sur de Francia, para dictar una conferencia sobre Hegel y los griegos. Entre el público estaba Fédier. Él tenía veintidós años, Heidegger estaba en sus sesenta y nueve. "Posteriormente, no dejé de verlo hasta 1974, dos años antes de su muerte. Así es que pude observar a este hombre durante casi veinte años".

Pascal David, filósofo francés, indica que Fédier trabajó en la elaboración de nuevas vías para traducir e interpretar rigurosamente el pensamiento de Heidegger; además, formó a numerosos traductores en la experiencia de traducir, entre los que se cuenta el propio Pascal David. Su trabajo, agrega, no ha cesado de implicar las más altas exigencias en lo que se refiere a las traducciones de Heidegger, lo cual ha conllevado el hecho de no ceder nunca a las facilidades de una traducción convencional, académica. Deja de lado el evasivo lenguaje estereotipado (la "langue de bois") para, con todo el rigor propio de la fenomenología, dar a ver y a entender aquello que vierte del alemán al francés. Si aceptamos que ha habido lo que se ha convenido en llamar una "recepción" de Heidegger en Francia -en el sentido positivo de esta expresión-, él no ha sido solamente la piedra angular. Es el alma misma de esa "recepción".

El filósofo chileno-español Francisco Soler Grima -discípulo de José Ortega y Gasset y Julián Marías- consideraba a François Fédier y a Jean Beaufret como los máximos exponentes del pensamiento surgido de las meditaciones de Heidegger. Afirma enfáticamente que Jean Beaufret junto con F. Fédier y un pequeño grupo de discípulos son quienes han tomado a Heidegger con la seriedad que hace al caso y continúan pensando, en fiel y libre discipulado, el ámbito pensante abierto por el maestro de Friburgo. Sin duda alguna, los Dialogue avec Heidegger, 3 vols., es lo mejor que acerca de Heidegger se ha publicado, junto con los breves tratados de Fédier (por ejemplo, "Parole-Poème-Sacré". Rev. Liberté de Montreal), prólogos y notas iluminadoras a sus traducciones de Heidegger. ¡Beaufret y Fédier están pensando en Francia! ${ }^{6}$.

Jorge Eduardo Rivera, a quien debemos la segunda traducción de Sein und Zeit al castellano, manifiesta que, por una parte, el constante diálogo con el profesor Friedrich-Wilhelm von Herrmann y, por otra, conversaciones ocasionales con el profesor Hans-Georg Gadamer y con el profesor Max Müller ayudaron a la comprensión más

3 Eds. de la Universidad Diego Portales, Santiago, 2017.

4 Viña del Mar, 2019, en traducción de Francisco Méndez Labbé -quien falleció en febrero de 2021-, con prólogo de Abel González Rojas.

Véase, Le Dictionnaire Martin Heidegger, Cerf, Paris, 2013, p. 479.

Véase su prólogo a Filosofía, Ciencia y Técnica, Editorial Universitaria, Santiago, $7^{\mathrm{a}}$ ed., 2019, p. 55. 
exacta de algunos pasajes especialmente difíciles de esta obra fundamental de Heidegger. También debo mencionar aquí -agrega-algunos encuentros con François Fédier y con el traductor francés de Sein und Zeit, François Vezin, quienes tuvieron a bien examinar algunos puntos particulares del texto. El resultado fue un texto muchísimo más límpido y comprensible ${ }^{7}$.

Participa el año 1965 en la travesía Amereida, que parte desde Chile, pasa por Argentina y llega a Bolivia, proyectando inicialmente llegar a Venezuela, de acuerdo a lo que indica Fédier en el video "La invención de un mar. Amereida 1965/2017", debido al cineasta chileno Javier Correa. Además, fue uno de los fundadores de la Ciudad Abierta, situada al norte de Valparaíso. Estos y otros hechos muestran la especial cercanía suya a nuestro país.

En 1981 tuve la suerte y el honor de participar en un seminario dirigido por él en Santiago acerca de pensar y ser en Heidegger, que tuvo como base la carta que el filósofo dirige a Hartmut Buchner, recogida posteriormente como epílogo de la conferencia "La cosa" (una versión de esta carta al castellano -debida al mismo Fédier, Francisco Soler y María Teresa Poupin-aparece en Filosofía, Ciencia y Técnica). Redacté los protocolos que, en su momento, recibieron la aprobación del filósofo francés. Se trata de algo único. En efecto, aunque Fédier impartió varios cursos y dirigió varios seminarios en nuestro país, solo el seminario sobre una "Carta a un joven estudiante", de Heidegger, cuenta -por lo que a mi conocimiento se hace- con protocolos que dan cuenta de sus lecciones en Chile, proporcionando un testimonio escrito de sus viajes filosóficos a este lugar de Sudamérica, al que vino por vez primera en 1962. A este seminario asistieron prominentes miembros de nuestra intelectualidad, como Mario Góngora del Campo, Godofredo Iommi Marini, Eduardo Kähs Loyola -prematuramente desaparecido-, Héctor Carvallo Castro, quien falleció en mayo de 2020, Miguel Eyquem Astorga, cuyo deceso se produjo en marzo de 2021.

Dadas las características de este seminario, el director de Mapocho, mi amigo Carlos Ossandón Buljevic, acogió los protocolos correspondientes en el número 81 de esta revista de Humanidades editada por la Biblioteca Nacional. Los nombres de todos los integrantes del seminario aparecen al comienzo de los protocolos. En ellos se muestra de qué manera es posible abordar fructíferamente el pensamiento del filósofo de Friburgo a partir de un breve escrito suyo, "Carta a un joven estudiante", teniendo como horizonte una parte significativa de sus textos, los problemas de nuestra época-la era de la técnica moderna- y la historia de la filosofía, desde Anaximandro en adelante.

En los años siguientes, Fédier tuvo la gentileza y la generosidad de enviarme sus publicaciones -libros, artículos, traducciones. Mantuvimos correspondencia-primero por cartas, luego por el correo electrónico. En cierto momento, mi amigo Jaime Sologuren y yo hicimos traducciones de textos suyos. Esa tarea culminó en la edición y publicación de Voz de amigo, en la que participaron también Miguel Eyquem, Pablo Ortúzar, Federico Camino y Fernando Guerrero. En la obra se recogió la traducción 
de Francisco Soler de una carta de Fédier a Robert Marteau que versa sobre la palabra, el poema y lo sagrado.

Continué traduciendo escritos suyos sobre arte y sobre cómo leer la obra de Heidegger. Respecto de los primeros: en ellos no hay una meditación acerca del arte y solo de él, abstractamente considerado -aunque ya eso sería suficiente. Junto con pensar sobre dicho fenómeno, Fédier va reflexionando sobre el ser del hombre, acerca de lo que es el ser humano y de lo que tendría que ser para estar a la altura de sí mismo. En ellos se podrá encontrar pensamientos de la mayor importancia respecto de la vida humana -histórica, en el mundo y conviviendo con los otros hombres- que esclarecen la propia existencia. Es decir, aunque el autor toma muy en cuenta el pensamiento y la obra de los artistas mismos -pintores, músicos, poetas-y no solo las teorías estéticas, esos textos están escritos desde un punto de vista estrictamente filosófico.

Respecto de los segundos: se sale al paso de malinterpretaciones de Heidegger, filósofo que mueve -a través de Jean Beaufret-el quehacer pensante de Fédier. Al mismo tiempo, en ellos se proporcionan claves de intelección de la vida y el pensamiento de Heidegger que permiten comprenderlos de acuerdo a su efectiva realidad, lo que, por cierto, redunda en beneficio del lector. Dicho de otro modo: Fédier continúa-ciertamente, de manera muy personal- el filosofar de Heidegger y Beaufret. Para entender ese filosofar tal como es surge la necesidad de desmontar los prejuicios descaminados y desorientadores respecto del pensador alemán, así como bosquejar vías de acceso a su obra que sean fecundas para quienes se acercan a ella. Nuestro autor se ha dedicado a ambas tareas de manera ejemplar. El llamado de Fédier al lector es que se asuma a sí mismo como alguien escrupuloso y responsable, de modo tal que sea beneficiado con la lectura de Heidegger, puesto que, según él, "la experiencia muestra que todo lector que aborda serenamente el pensamiento de este autor no tarda en entender cómo ese pensamiento hace un llamamiento a lo mejor de él — lo que nunca, en nadie, falta del todo"s.

En 2019 Fédier publica su último libro: Tenir Entretenir S'entretenir, cuyo título es de difícil traducción. Gentilmente me escribió para aclararme cómo tenía que verterlo al castellano: "Una observación sobre el título: -En francés las tres palabras giran en torno al verbo "tenir" - tomado en su sentido más inmediato -el que habla en la locución "tenir bon" = esforzarse por ser firme, no dejarse llevar-. Entretenir (por ejemplo, "cuidar un jardín") significa no dejar de cuidarlo para que siempre esté en su mejor forma. También podemos decir: cuidar su salud. -En cuanto a s'entretenirdebe ser entendido desde el significado de "entretenir" como: cuidar las relaciones con los demás, por lo tanto: hablar con los demás, es decir, en primer lugar, escucharlos". Traduje, pues, "Firmeza Cuidado Escucha".

En su plena madurez, Ortega hace algunas observaciones acerca de la manera de pensar, el estilo y el método filosófico de Heidegger. Dice, en primer lugar, que quiero

8 "Cinco preguntas a propósito de Heidegger"; Limite Volumen 12, № 39, Arica (Chile), 2017, p. 85. 
parecerme a nuestro gran Heidegger, que no gusta, como los otros hombres, de detenerse solo en las cosas, sino sobre todo -y esto es muy peculiar en él- en las palabras ${ }^{9}$. En segundo término, señala que el estilo filosófico de Heidegger, tan egregiamente logrado, consiste sobre todo en etimologizar, en acariciar a la palabra en su arcana raíz ${ }^{10}$. Y explicitando lo anterior, indica que Heidegger toma una palabra [...] y le saca virutas. Poco a poco, del minúsculo vientre del vocablo, van saliendo "humanidades", todos los dolores y alegrías humanas y, finalmente, el Universo entero. Heidegger, como todo gran filósofo, deja embarazadas a las palabras, y de éstas emergen luego los más maravillosos paisajes con toda su flora y toda su fauna ${ }^{11}$.

Pues bien, en "Firmeza Cuidado Escucha" podemos asistir a una manera insigne en que se asume -mediante una modulación muy personal-el modo de pensar, el estilo y el método del pensador de Friburgo. Fédier se detiene especialmente en las palabras, busca su verdadero sentido -lo que los antiguos llamaban el etymon de la palabra-y hace aparecer ante nuestros ojos realidades nunca vistas antes por nadie.

Ojalá la obra de Fédier alcance mayor presencia en el ámbito de lengua castellana; sin duda, para beneficio de los hispanohablantes. Sería la mejor manera de recordar a tan prominente trabajador y cultivador de la filosofía, inscrito en la per-duración del pensar.

Trayendo a la memoria las palabras de René Char frente a la muerte de Albert Camus, digamos, en referencia a François Fédier: con el que queremos dejamos de hablar, pero no se ha hecho el silencio.

"El mito del hombre allende la técnica". Obras Completas VI, Ed. Taurus, Madrid, 2006, p. 811 .

10 "En torno al "Coloquio de Darmstadt, 1951"”. Ibid., p. 808.

$11 \quad$ Ibid., pp. 802, 808, 806. 